\title{
PENGARUH ENERGI PEMADATAN TERHADAP NILAI KEPADATAN TANAH
}

\author{
Dian Hastari Agustina ${ }^{1)}$, Yopi Latul ${ }^{2)}$ \\ ${ }^{1,2)}$ Program Studi Teknik Sipil, Fakultas Teknik, Universitas Riau Kepulauan \\ E-mail: dian_rajendra@yahoo.com ${ }^{1)}$, yopilatul19@gmail.com ${ }^{3)}$
}

\begin{abstract}
ABSTRAK
Tanah merupakan material yang sangat penting sehingga harus mampu mendukung beban yang berada di atasnya, maka tanah harus mempunyai daya dukung tanah yang cukup baik. Parameter kekuatan dan deformasi tanah terkait dengan kepadatannya. Tanah timbunan dengan kualitas yang baik memerlukan pemadatan agar memperoleh tanah yang stabil dan memenuhi persyaratan teknis untuk membangun suatu struktur. Pada penelitian ini membandingkan energi pemadatan tanah metode proctor tes dengan metode proctor modified. Energi pemadatan adalah faktor penting dalam menentukan kekuatan tanah yang harus dipertimbangkan selama fase perencanaan. Dari hasil penelitian ini diperoleh nilai kepadatan Standard Proctor di laboratorium sebesar 1,63 gram $/ \mathrm{cm}^{3}$ dan kepadatan modified proctor sebesar $2.18 \mathrm{gr} / \mathrm{cm}^{3}$. Hasil pengujian kepadatan dengan sand cone diperoleh nilai derajat kepadatan sebesar $97.31 \%$ pada pemadatan dengan standar proctor test, sehingga kepadatan yang dibutuhkan telah tercapai dan tanah bisa digunakan dalam pekerjaan timbunan, tetapi jika dibandingkan dengan kepadatan modified proctor test diperoleh nilai kepadatan 73.54\% lebih kecil $23.77 \%$ dari kepadatan di laboratorium dengan uji standard proctor.
\end{abstract}

Kata kunci : energi pemadatan, uji standar proctor, uji proctor modifikasi

\section{ABSTRACT}

Soil is a very important material for structures as must be able to support the load applied, that's why soil must have a sufficiency of bearing capacity Strength and deformation parameters are related to the dry density. Good quality of embankment requires to compaction to obtain a stable soil and to fulfill the technical requirements to build a structure. This study compared the soil compaction energy proctor test method with the modified proctor method. Compaction energy is an important factor in determining the strength of the soil that must be considered during the planning phase. From the results of this study, the value of Standard Proctor density in the laboratory was $1.63 \mathrm{gr} / \mathrm{cm}^{3}$ and the modified proctor density was $2.18 \mathrm{gr} / \mathrm{cm}^{3}$. The result of soil density of sand cone test shows that degree of soil density is $97.31 \%$ for standard proctor test method, then the soil density has reached and the soil embankment can use, but if compared by modifying compaction test methods, the degree of soil density is $73.54 \%$ lower than the soil density in the laboratory by standard proctor test.

Keyword: Compaction energy, standard proctor test, modified proctor test

\section{PENDAHULUAN}

Tanah merupakan material yang sangat penting untuk konstruksi bangunan gedung, jalan, maupun bendungan sebagai penyangga dan penyalur beban pondasi dari konstruksi bangunan yang ada di atas permukaan tanah. Dimana pada saat akan dilakukan suatu pekerjaan 
pembangunan konstruksi di daerah tertentu, maka tanah di daerah tersebut harus mempunyai daya dukung tanah yang cukup dan melebihi beban kapasitas keseluruhan konstruksi bangunan yang disalurkan terhadap pondasi.

Pemadatan tanah merupakan salah satu usaha secara mekanik agar butir-butir tanah merapat, volume tanah akan berkurangseiring dengan berkurangnya volume pori. Namun, volume butir tidak berubah. Pemadatan dpat dilakukan dengan cara menggilas atau menumbuk (Santosa, dkk, 2015).

Pemadatan sering digunakan dan dipertimbangkan oleh banyak insinyur dalam desain. Kepadatan kering tanah dan kadar air dapat dikontrol dalam batas selama konstruksi untuk mengungkapkan sifat-sifat tanah (kepadatan, CBR, konsolidasi, permeabilitas, kekuatan geser, dll.). Pemadatan tanah memainkan peran penting dalam konstruksi struktur, jalan raya, bandara dan embankment pada bendungan. Usaha pemadatan yang berbeda adalah salah satu dari beberapa faktor penting lainnya yang mempengaruhi pemadatan tanah. Proctor (1933), menyatakan hubungan antara kepadatan $\left(\gamma_{\mathrm{d}}\right)$ dengan kadar air $\left(\gamma_{\mathrm{w}}\right)$ ke dalam grafik, yang bisa dilihat dalam Gambar 1.

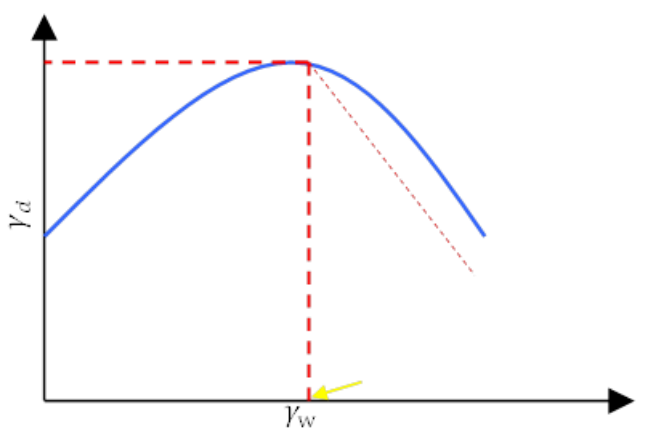

Gambar 1. Hubungan antara kepadatan $\left(\gamma_{\mathrm{d}}\right)$ dengan kadar air $\left(\gamma_{\mathrm{w}}\right)$

Percobaan di laboratorium yang sering dilakukan untuk mendapatkan berat volume kering maksimum dan kadar air optimum adalah dengan uji pemadatan proctor (Proctor Compaction Test). Metode uji pemadatan dalam proctor compation test adalah uji standar proctor (standard proctor test) dan uji proctor modifikasi (modified proctor test). Penelitian ini dilakukan untuk membandingkan hasil pengujian pemadatan di laboratorium dengan metode standard proctor test dan modified proctor test yang selanjutnya dibandingkan dengan hasil pemadatan yang ada di lapangan dengan menggunakan pengujian sand cone test.

\section{LANDASAN TEORI}

Tanah kohesif kering merupakan tanah yang sukar dipadatkan. Jika ditambahkan air, tanah menjadi lunak dan lebih mudah dipadatkan,tapi makin besar kadar air tanah makin membatasi kepadatan yang dapat dicapai. Udara tanah mulamula Telah dipadatkan maksimum yang dapat berkurang hanya udara, jika volume air lebih besar maka kepadatan maksimum berkurang. Tanah kenyang air tidak dapat dipadatkan. Pada dasarnya, makin basah tanah makin mudah dipadatkan. Karena air berfungsi sebagai pelumas agar butir-butir tanah mudah merapat. Tapi kadar air yang berlebihan akan mengurangi hasil pemadatan yang dapat dicapai (Hardiyatmo, 2002).

Manfaat dari Pemadatan bertujuan untuk memperbaiki sifat teknis untuk memperoleh keadaan tanah yang paling padat, sehingga dapat:

1) Memperbaiki kuat geser tanah,

2) Mengurangi komprebilitas yaitu penurunan oleh beban,

3) Mengurangi permeabilitas, dan

4) Mengurangi sifat kembang susut tanah.

Pada pemadatan tanah dengan tenaga pemadatan tertentu akan menghasilkan kepadatan tertentu juga. Kadar Air terbaik untuk menghasilkan kepadatan yang tinggi disebut Kadar Air Optimum $($ Optimum Moisture Content $)=\mathrm{OMC}=$ Wopt. Kepadatan terbesar disebut juga berat volume kering maksimum(Maximum Dry Density) $=$ MDD .

Hubungan berat volume kering $(\gamma d)$ dengan berat volume basah $(\gamma b)$ dan Kadar Air (w), dinyatakan dalam persamaan :

$$
\gamma_{d}=\frac{\gamma b}{1+w}
$$


Berat volume kering setelah pemadatan bergantung pada jenis tanah, Kadar Air, dan usaha yang diberikan oleh alat penumbuknya.Karakteristik kepadatan tanah dapat dinilai dari pengujian pemadat standar laboratorium.

Pengujian pemadatan dengan Modified Proctor sama dengan pengujian Standard Proctor. Perbedaannya hanya terletak pada energi yang digunakan dan jumlah lapisan, seperti ditunjukkan pada tabel 1 .

Energi pemadatan dapat dinyatakan dalam

$$
E=\frac{N b N i W H}{V}
$$

Dimana $: E=$ energi Pemadatan $\left(\mathrm{kg}-\mathrm{cm} / \mathrm{cm}^{3}\right)$

$$
\begin{aligned}
& N b=\text { jumlah pukulan perlapis } \\
& N i=\text { jumlah lapisan } \\
& W=\text { berat pemukul }(\mathrm{kg}) \\
& H=\text { tinggi jatuh }(\mathrm{cm}) \\
& V=\text { volume mould }\left(\mathrm{cm}^{3}\right)
\end{aligned}
$$

\begin{tabular}{|c|c|c|c|c|c|c|}
\hline & $\begin{array}{c}\text { Diameter } \\
\text { tabung }\end{array}$ & $\begin{array}{l}\text { Volume } \\
\text { tabung } \\
\left(\mathrm{cm}^{3}\right)\end{array}$ & $\begin{array}{c}\text { Berat } \\
\text { penumbuk } \\
\text { (rammer) }\end{array}$ & $\begin{array}{l}\text { Tinggi } \\
\text { jatuh }\end{array}$ & $\begin{array}{l}\text { Jumlah } \\
\text { tumbukan } \\
\text { per lapis }\end{array}$ & $\begin{array}{l}\text { Jumlah } \\
\text { lapis }\end{array}$ \\
\hline $\begin{array}{l}\text { Standard } \\
\text { Proctor }\end{array}$ & $\begin{array}{c}101,6 \mathrm{~mm} \\
(4 \mathrm{in})\end{array}$ & $\begin{array}{l}943,3 \\
\left(\mathrm{~cm}^{3}\right) \\
\left(1 / 30 \mathrm{ft}^{3)}\right.\end{array}$ & $\begin{array}{l}2,475 \mathrm{~kg} \\
(5,5 \mathrm{lbs})\end{array}$ & $\begin{array}{l}308,4 \\
\mathrm{~mm} \\
(12 \text { in })\end{array}$ & 25 & 3 \\
\hline \multirow[t]{2}{*}{$\begin{array}{l}\text { Modified } \\
\text { Proctor }\end{array}$} & $\begin{array}{c}101,6 \mathrm{~mm} \\
(4 \mathrm{in})\end{array}$ & $\begin{array}{l}943,3 \\
\left(\mathrm{~cm}^{3}\right) \\
\left(1 / 30 \mathrm{ft}^{3)}\right.\end{array}$ & \multirow[t]{2}{*}{$\begin{array}{l}4,50 \mathrm{~kg} \\
(10 \mathrm{lbs})\end{array}$} & \multirow{2}{*}{$\begin{array}{c}45,72 \\
\mathrm{~mm} \\
(18 \mathrm{in})\end{array}$} & 25 & \multirow[t]{2}{*}{5} \\
\hline & $\begin{array}{l}152,64 \mathrm{~m} \\
\mathrm{~m}(6 \mathrm{in})\end{array}$ & $\begin{array}{c}2124\left(\mathrm{~cm}^{3}\right) \\
\left(3 / 40 \mathrm{ft}^{3}\right)\end{array}$ & & & 56 & \\
\hline
\end{tabular}

Tabel 1. Perbedaan pemadatan standard proctor dan

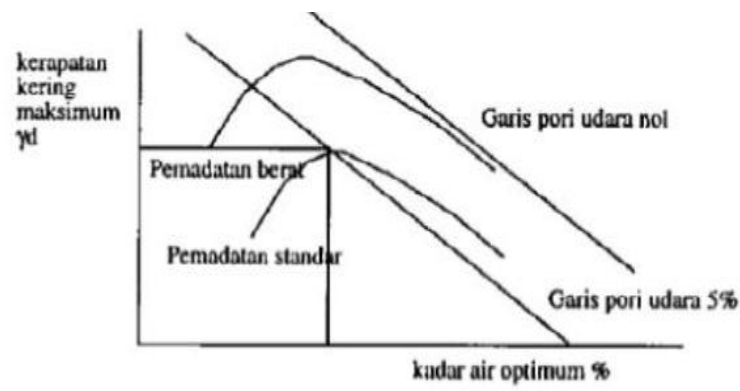

Gambar 2. Kurva pemadatan

\section{METODE PENELITIAN}

Dari hasil pengujian properties tanah diperoleh data yang dapat dilihat dalam tabel di bawah ini.
Tabel 2. Data properties tanah

\begin{tabular}{cc}
\hline Parameter Tanah & nilai \\
\hline Kadar air (\%) & 17.8 \\
\hline Batas cair (\%) & 41.67 \\
\hline Batas plastis (\%) & 28.25 \\
\hline Indeks plastisitas (\%) & 13.42 \\
\hline Batas susut (\%) & 17.81 \\
\hline Berat Jenis & 2,57 \\
\hline $\begin{array}{c}\text { Kerikil, persentasi tertahan saringan } \\
\text { ukuran 4,75 mm (\%) }\end{array}$ & 0 \\
$\begin{array}{c}\text { Butiran kasar, persentasi tertahan } \\
\text { saringan ukuran 0.075 mm (\%) }\end{array}$ & 84.94 \\
$\begin{array}{c}\text { Butiran halus, persentasi lolos saringan } \\
\text { ukuran 0.075 mm (\%) }\end{array}$ & 69.92 \\
\hline $\begin{array}{c}\text { Klasifikasi USCS / AASHTO } \\
\text { CL / }\end{array}$ & A-7-5 \\
\hline
\end{tabular}

\subsection{Pemadatan Tanah}

Pemadatan tanah dengan dilakukan untuk mencari nilai kadar air optimum dan berat kering maksimum, penelitian ini menggunakan sampel tanah yang lolos saringan no. 4 dan telah kering oven. Untuk mendapatkan kurva kadar air optimum/ optimum moisture content (OMC) dan berat kering maximum/ maximum dry density (MDD). Pemadatan dilakukan dengan 2 metode seperti yang tertera pada tabel 1 .
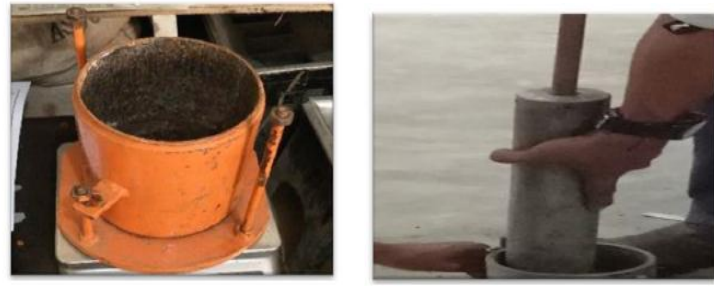

Gambar 3. Pemadatan di laboratorium

\subsection{Pengujian Sand Cone}

Dari hasil pengujian kepadatan tanah dilapangan dengan menggunakan sand Cone bertujuan untuk memeriksa kepadatan tanah di lapangan secara langsung. Dari berat tanah dan volume tanah akan didapatkan densitas/berat volume tanah $(\gamma \mathrm{t})$, selanjutnya tanah di oven dan didapat kadar air (w), dan densitas/berat volume tanah kering $(\gamma d)$. Dari $\gamma d$ lapangan dan $\gamma d$ tanah hasil uji laboratorium didapatkan derajat kepadatan. 


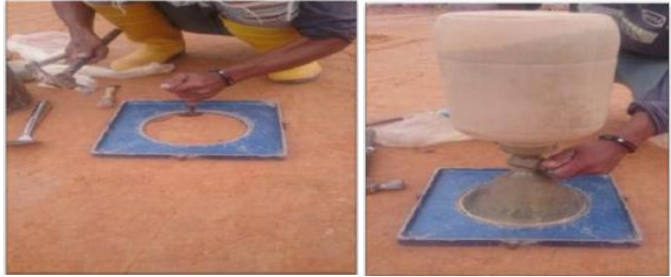

Gambar 4. Pengujian sand cone di lapangan

\section{HASIL DAN PEMBAHASAN}

Dari hasil pengujian yang dilakukan terhadap pengujian standard proctor test pada tanah di Desa Sijantung didapatkan nilai berat isi tanah kering maksimum (Maximum Dry Density= $\gamma \mathrm{d}_{\max }$ ) sebesar 1.64 gram/cm3, yang berarti lebih kecil dibandingkan dengan hasil pengujian $\gamma \mathrm{d}_{\max }$ modified proctor test sebesar $2.18 \mathrm{gr} / \mathrm{cm} 3$, atau naik $32.92 \%$ dari nilai kepadatan dengan standard proctor test.

Kadar air maksimum $\left(\mathrm{W}_{\text {opt }}\right)$ atau Optimum Moisture Content (OMC) modified sebesar $13.8 \%$ lebih kecil dibanding $\mathrm{W}_{\mathrm{opt}}$ standard proctor dengan nilai kadar air sebesar $15 \%$, atau turun $8 \%$.

Hal ini sesuai dengan teori yang mengatakan suatu tanah yang sama bila dipadatkan dengan cara standard dan cara modified diperoleh (Das, 1995) :

(MDD) $\gamma \mathrm{d}_{\max }$ modified $>\gamma \mathrm{d}_{\max }$ standard

(OMC) $\mathrm{W}_{\mathrm{opt}}$ modified $<\mathrm{W}_{\mathrm{opt}}$ Standard

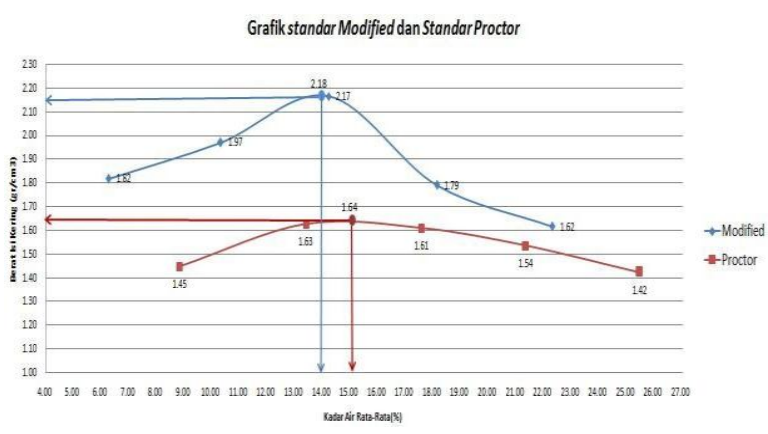

Gambar 5. Grafik Pemadatan Modified Proctor dan Standar Proctor

Dari hasil pengujian kepadatan tanah di lapangan dengan menggunakan sand cone diperoleh nilai derajat kepadatan sebesar $97.31 \%$ pada pemadatan dengan standar proctor test, sehingga kepadatan yang dibutuhkan telah tercapai dan tanah bisa digunakan dalam pekerjaan timbunan, tetapi jika dibandingkan dengan kepadatan modified proctor test diperoleh nilai kepadatan $73.54 \%$ lebih kecil $23.77 \%$ dari kepadatan di laboratorium dengan standard proctor.

Tabel 3. Perbandingan hasil pemadatan Standard proctor test dengan Modified proctor test

\begin{tabular}{|l|c|c|}
\hline & $\begin{array}{c}\text { Standard } \\
\text { proctor test }\end{array}$ & $\begin{array}{c}\text { Modified } \\
\text { proctor test }\end{array}$ \\
\hline MDD $\left(\mathrm{gr} / \mathrm{cm}^{3}\right)$ & 1.64 & 2.18 \\
\hline OMC (\%) & 15 & 13.8 \\
\hline $\begin{array}{l}\text { Derajat Kepadatan } \\
\text { lapangan (\%) }\end{array}$ & 97.31 & 73.54 \\
\hline
\end{tabular}

\section{KESIMPULAN}

Hasil pengujian indeks propertis diperoleh Kadar Air tanah sebesar $17.38 \%$. Berat Jenis Tanah sebesar 2.57\%. Dari hasil uji Atterberg limit Sijantung Sei Gong - Batam menunjukan Batas Cair sebesar 41.67\%. Batas Plastis sebesar $28.25 \%$. dan indeks plastisitas sebesar 13.42\%. Hasil dari uji Atterberg Limit tanah yang terdapat di desa Sijantung, Sei Gong Batam mempunyai tingkat penyusutan yang sedang mencapai 41,18\%. Hasil pengujian analisis saringan diperoleh sebanyak $69.92 \%$ tanah lolos saringan 200.

Sampel tanah yang digunakan dalam penelitian ini berdasarkan system klasifikasi AASHTO digolongkan pada kelompok A-7-5 (tanah berlempung). Tanah lempung yang lebih bersifat plastis dan mempunyai sifat perubahan yang cukup besar dan klasifikasi USCS tanah tersebut digolongkan kedalam kelompok CL(Lempung anorganik). Jika kedua klasifikasi tanah tersebut dibandingkan menggunakan perbandingan klasifikasi tanah unified dengan AASHTO, tanah tersebut memiliki kesamaan dalam klasifikasinya.

Kepadatan tanah standar proctor test dan modified proctor test di laboratorium sebe 1,64 $\mathrm{gram} / \mathrm{cm}^{3}$ dan $2.28 \mathrm{gram} / \mathrm{cm}^{3}$, dengan nilai OMC sebesar $15 \%$ dan 13.8\%. Derajat kepadatan yang diperoleh dari hasil pengujian di lapangan dengan menggunakan alat Sand Cone didapat nilai derajat kepadatan standard proctor yaitu $97,31 \%$ (derajat kepadatan yang 
memenuhi syarat karena nilainya $>95 \%$ ) dan nilai derajat kepadatan modified proctor 73.54\% (tidak memenuhi standar karena < 95\%). Jika dari hasil pengujian pemadatan di lapangan, tanah timbunan tersebut sudah memenuhi persyaratan untuk perencanaan subgrade maupun fondasi jalan, tetapi jika tanah timbunan tersebut merupakan tanah timbunan ntuk perencanaan dasar bendungan yang biasanya menggunakan modified proctor test, maka hasil pemadatan tersebut masih belum memenuhi standar.

Energi pemadatan yang lebih besar menghasilkan nilai kepadatan yang lebih tinggi.

\section{DAFTAR PUSTAKA}

[1] Bowles, J. E. Sifat-sifat Fisis dan Geoteknis Tanah. Erlangga: Jakarta. 1991.

[2] Das, B. M. Mekanika Tanah (Prinsip Prinsip Rekayasa Geoteknik) Jilid 1. Erlangga: Jakarta. 1993.

[3] Hardiyatmo, H. C. Mekanika Tanah I. Universitas Gajah Mada Press: Yogyakarta. 2012

[4] Santoso, B., Suprapto, H., Hs, Suryadi. Dasar Mekanika Tanah. Guna Darma. 2015

[6] Yudistira,Y., Permana,S., dan Farida, I. Analisa kepadatan tanah pada timbunan di saluran irigasi dengan metode pengujian Proctor dan Sand Cone. Konstruksi Sekolah Tinggi Teknologi. Garut.Vol.13 no 1 hal 118, 2015. 